\title{
NUEVA DIRECTORA DEL INSTITUTO
}

El 11 de diciembre de 1990 tomó posesión como directora del Instituto de Investigaciones Estéticas la maestra Rita Eder Rozencwaig, en sustitución de la doctora Elisa García Barragán. La maestra Eder es investigadora de tiempo completo del Instituto desde $1975 \mathrm{y}$, entre otros trabajos, ha publicado Gironella, Dadá. Documentos de arte y Teoria social del arte. Con respecto a su desempeño en las nuevas tareas del Instituto, la directora reconoció, en la ceremonia de posesión, que la Universidad Nacional Autónoma de México es el lugar donde recibió gran parte de su formación académica; aquí absorbió sus lecciones más marcantes y formó sus afectos más profundos. En presencia de los coordinadores de Humanidades y de Difusión Cultural, de la directora saliente y los miembros del personal académico del Instituto, la maestra Eder aseguró que se hallaba ante una gran responsabilidad y que deseaba corresponder, en la medida de sus fuerzas y posibilidades, la confianza que sus colegas le habían brindado para su designación como directora. Además, afirmó: "Tenemos el privilegio de ser una Institución única en su género dedicada a la investigación en los distintos campos del arte. La libertad de cada investigador de proseguir sus proyectos dentro de sus ideales y capacidades aparece protegida por las leyes de esta Universidad, que la rigen en un espíritu abierto y respetuoso de las ideas. Cuando las he examinado he pensado y sentido que es un baluarte del que debemos sentirnos orgullosos y que nos obliga noblemente a no defraudarla.

"Estoy consciente de que este Instituto de larga tradición y altas metas debe proponerse proseguir niveles de excelencia académicos que en muchos sentidos ya ha alcanzado bajo las distintas personalidades que lo han regido. Ello depende del trabajo individual de cada uno, pero también de nuestra habilidad y deseo de convertirnos en una comunidad activa en proyectos y actitudes colectivas. El Instituto de Investigaciones Estéticas es rico en sus distintos sectores: investigación, archivos, fototeca, biblioteca y el sector administrativo, que forman una estructura indispensable para la existencia de esta Institución.

"De los proyectos de trabajo, muchos pensados y conversados con técnicos e investigadores, habría de puntualizar aquellos que se refieren a una obra de conjunto indispensable, en el campo de la investigación sobre arte mexicano y la modernización de la Fototeca, ya iniciada por la Dra. García Barragán, hasta convertirla en un banco de datos sobre los distintos aspectos del arte mexicano, latinoamericano 
y, a la larga, universal. Queremos una relación de trabajo con las distintas instituciones dedicadas a las artes y con otros institutos en la Universidad; también nos preocupa acercarnos a los creadores y a sus procesos de trabajo.

"Deseo servir al Instituto de Investigaciones Estéticas en sus deseos de superación académica, en su viva ilusión de una conciliación que abarque todos los sectores del Instituto, seguir su trayectoria como un lugar para el desarrollo profesional en donde no tenga lugar, en ninguna de sus formas, el abuso de autoridad.

"Hoy quiero comprometerme y comprometerlos a todos y cada uno de los que forman parte del Instituto a dar lo mejor de sí para el mayor éxito de este nuestro lugar y de esta nuestra Universidad". 